\title{
Price Determinants of Stock-Type Horses Sold at Public Online Auctions
}

\author{
Michelle L. Kibler ${ }^{1 \rtimes \star(D)}$ and Jada M. Thompson ${ }^{2}$ \\ ${ }^{1}$ Illinois State University, Department of Agriculture, Normal, Illinois, 61790-5020 and ${ }^{2}$ University of Tennessee, Department \\ of Agricultural and Resource Economics, Knoxville, Tennessee, 37996 \\ ${ }^{\star}$ Corresponding author. Email: mlkible@ilstu.edu
}

\begin{abstract}
There is a shift in livestock auction sales in consolidation of live markets and movement toward virtual marketplaces. We examine buyer preferences for nonracing stock-type horses sold through virtual auctions to better understand how animals are sold and their valuation. A shift towards online sales of equine has impacted the number of potential buyers through increased exposure to sale horses. Using data collected from online auctions, we estimate factors influencing propensity to sell as well as price determinants in this market platform. We find many factors contribute to the likelihood of a horse selling and to the final sale price.
\end{abstract}

Keywords: agribusiness; equine; hedonic price analysis; internet auction; stock-type horse

JEL Classifications: Q11; Q13; D11

\section{Introduction}

The platform of a central marketplace has evolved from ancient agoras and open-air markets to modern, virtual marketplaces such as online sales websites and social media groups with individuals looking to buy or sell goods. Equine marketplaces have followed this trend with the emergence of websites created to buy and sell horses, online auction websites and more recently, the development of virtual marketplaces via social media platforms. The development of virtual markets provides the opportunity to market horses to a larger group of buyers who no longer need to travel to a live auction site to view and potentially purchase the animal. Online auctions likely increase the number of potential buyers for any given horse and provide insight into consumer preferences for the horses purchased through the auction. The emergence of online sales has impacted public live auctions and changed the landscape of the marketing of horses and other livestock. For instance, from 2002 to 2019 there has been an increase of internet sales of cattle by $4 \%$ (USDA-AMS, 2020). The prices paid for a horse no longer reflects only the selection of horses at a given auction, but a larger selection where listed sale horses and potential buyers cover a greater geographical area. The access to information has changed from word of mouth, to sale books, and finally to seller provided data online. Previous work investigating the impact horse-specific attributes have on prices received for stock-type horses sold at auction does not account for these changing preferences and how this information can change buyer behavior. This study aims to provide an updated estimation of attribute-specific contributions to sales price in the presence of the current marketing system with a modernized investigation into buyer demands and update the propensity to sell for all horses entered into the online auction accounting for changing access to information.

(C) The Author(s) 2020. This is an Open Access article, distributed under the terms of the Creative Commons Attribution licence (http:// creativecommons.org/licenses/by/4.0/), which permits unrestricted re-use, distribution, and reproduction in any medium, provided the original work is properly cited. 


\section{Background}

Individuals looking to purchase a horse may be searching for a combination of attributes: level of training, breed, age, sex, height, pedigree, success in showing or competitions, success of progeny, and color, among other factors. Sellers marketing their horse(s) provide information to attract buyers and convey value. When a seller has elected to utilize online auctions to sell a horse, they advertise the horse through physical description, explanation of training, competition experience/ success, and pedigree success. In traditional, live auctions, buyers have first-hand samples of the horse's performance. In order to compensate for the lack of in-person visual inspection, sellers often provide pictures and, occasionally, video of the horse for further evaluation by the potential buyer.

In any market platform, sellers of horses may possess more information regarding the horse to be sold than potential buyers. Therefore, the decision to bid and ultimately purchase a horse must be made from the information presented to the buyer from the seller. Auctions, unlike personal sales between buyer and seller, often offer mechanisms to mitigate asymmetric information between buyer and seller. To reduce asymmetric information and decrease possible market failures, auctions frequently employ policies (e.g., conditions of sale and required disclosures) for information disclosure requirements from the seller with repercussions, including the termination of a sale, if those policies are violated.

Horses used for recreation and competition are primarily bought and sold through personal interaction, sale websites, and, more recently, social media outlets while less frequently through auctions. Online auctions provide many benefits over live auctions and person-to-person sales, reducing risk of disease spread, decreased risk of injury to the horse due to transportation, increased number of potential buyers as they do not need to travel to the sale or even live in close proximity to the venue, and reduced cost to the seller presenting the horse for sale. For the potential buyer, online auctions may present a greater number of horses for the buyer to consider. While online auctions provide an opportunity to watch a video of the horse, many potential buyers may not have an opportunity to personally ride the horse, an action that is common in private sales but may be impossible in an online auction setting due to proximity of the horse for sale and buyer. Additionally, horses being considered greater distances away from the buyer represent increased transportation cost should the horse be purchased.

The majority of existing price determinant studies have investigated equine price determinants for thoroughbred racehorses. This is, in large part, due to the economic impact horse racing contributes to the larger equine industry and the amount of publicly available data from several annually recurring thoroughbred sales. These sales are typically organized by age with sales for weanlings, yearlings, two-year olds in training, or mixed sales (breeding stock or horses of all ages). Weanling and yearling thoroughbreds are close in age and experience as they have not yet begun training. Therefore, price determinants of these two groups are similar and have been found to belong to two categories: pedigree quality (stud fee, racing success throughout pedigree, and number of sire progeny representation at a given sale) and horse physical characteristics (sex, age, state of birth, health information, and sale order) (Hansen and Stowe, 2017; Vickner and Koch, 2001; Chezum and Wimmer, 1997; Plant and Stowe, 2013; Poerwanto and Stowe, 2010). As thoroughbreds age and progress in their training, price determinants begin to be influenced by speed over a specified distance in addition to pedigree quality and individual horse characteristics (Robert and Stowe, 2016). After a thoroughbred's racing career ends, most mares and a few select stallions enter breeding programs. For broodmares sold at auction, contributions to price sold are found to be influenced by stud fee, racing success of the mare and her offspring, sale order, and age (Maynard and Stoeppel, 2007; Neibergs, 2001).

While the majority of valuation studies in the equine literature have been conducted in the thoroughbred racing industry, several studies investigated attribute contribution to price for other sectors of the equine industry. Stowe and Kibler (2016) find age, physical limitations, sex, and 
color contribute to successful adoption of retired thoroughbreds entering second careers. One study conducted on quarter horse yearlings bred for racing finds sex and racing success of family members (dam, sire, granddams, and siblings,) to contribute to higher prices paid (Lansford et al., 1998). Taylor et al. (2006) explore price determinants of show quality quarter horses sold at the American Quarter Horse Association (AQHA) World Championship sale, an annual live public auction. The authors find age, gender, sex, notable show records, significant pedigree, sale order, and economic variables to contribute to sale prices. A pair of studies (Vestal et al., 2015; Taylor and Sieverkropp, 2013) find evidence that the ban on horse slaughter in the U.S. had a significant negative impact on horse values. The authors also find horse values were impacted by breed, sex, age color, and information provided in the horse's description including pictures contributed to sale prices. Bender and Stowe (2020) estimate buyer preferences for wild horses adopted through online auctions to include color, training level, age, height, sex, and seasonal trends.

This paper contributes to the literature as the first study that investigates price determinants for domesticated horses sold through monthly online auctions. This study is also an update of previous work estimating nonracing individual horse characteristics contribution to final sale price with the most recent study including data only up until 2014. The authors are unaware of any existing study which examines the influence the addition of a video to a horse's sale ad may have on sale price.

Market prices will be determined by estimating the effects individual horse characteristics such as age, color, performance record, and pedigree have on sale price. These factors contribute to market price and provide an understanding of the intrinsic value characteristics have for a given animal.

This article proceeds as follows. Section 3 describes the data and the empirical analysis to investigate study objectives. Section 4 describes the methods, section 5 describes results followed by a discussion, and Section 6 concludes.

\section{Data}

The data used for this analysis were collected from the Professional Horse Services, LLC online auction website for monthly sales from January 2013 through May 2019 (Professional Horse Services, LLC, 2019). Horses listed were stock-type horses with $88 \%$ quarter horse (registered or grade), $9 \%$ paint (registered or grade), and remaining 3\% include all other breeds listed in the sale. Conditions of sale exist to reduce asymmetric information and sellers must complete a required disclosures form for each entry. The auction requires sellers to accurately describe the horse and any major surgeries, serious injuries, colic surgery, history of lameness, or other abnormality/blemish. The inclusion of photos and video of the horse in the sale ad are encouraged but not required. Prospective buyers are permitted to contact the seller about the horse and conduct veterinary prepurchase examinations to verify health information about the horse. Like many auctions, sellers may set minimum prices for the horse and determine whether buyers will be given the reserve price selected.

Figure 1 shows the trends and variability in number of horses at auction, the count of horses sold, and the mean selling price for all years in the sample except 2019 which was excluded as it was an incomplete year of data. Two months consistently do not have online internet auctions with Professional Horse Services, October and November. Information was collected for all horses entered into the sale, and data summaries are provided in Table 1.

In addition to horse-specific information, temporal effects including individual month indicator variables $\left(\right.$ Month $\left._{i}\right)$ to capture seasonal trends in horse purchasing behavior and yearly $\left(\right.$ Year $\left._{i}\right)$ indicator variables to capture any overarching market changes are included.

Following the work by Taylor et al. (2006), horse characteristics were recorded to account for heterogeneity between horses and potential preferences by buyers. Horse characteristics include 


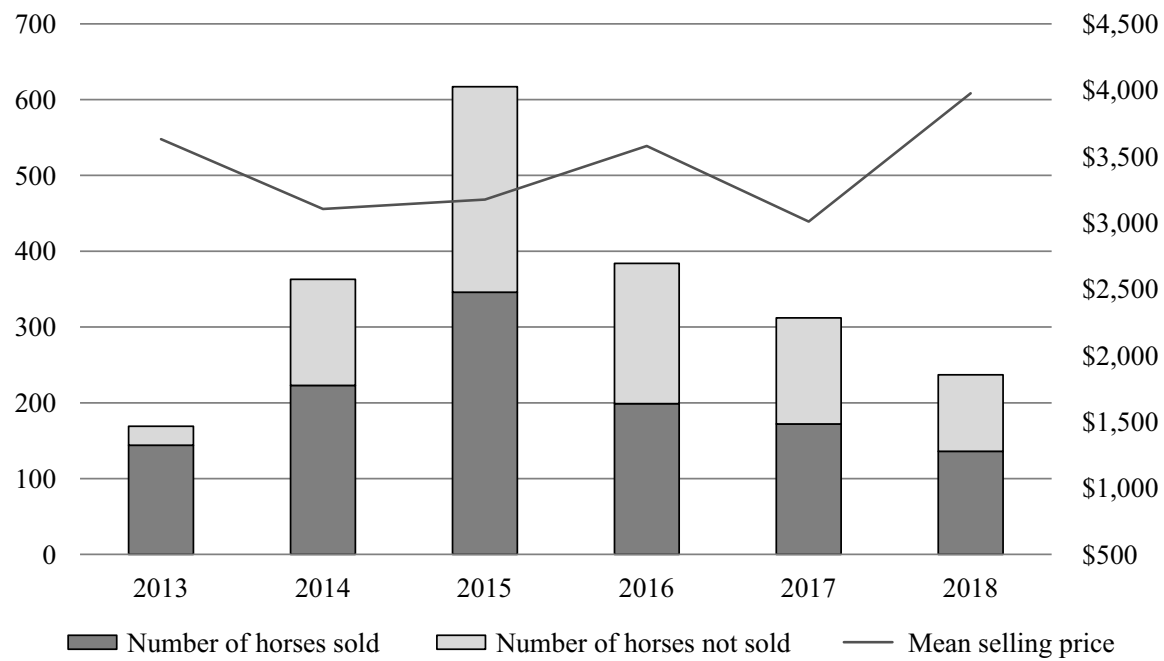

Figure 1. Annual horse internet auctions counts and mean selling price 2013-2018.

age (Age), age squared (Age2) which accounts for the declining value as horses have a shorter useful life, sex (Mare - which is a binary variable indicating female horses of any age and Gelding - which is a binary variable indicating whether the horse is a castrated male), height in inches (Height), breed (AQHA Breed - a binary variable indicating whether horse was registered with the AQHA), and color (Black, Buckskin, Chestnut, Gray, Palomino, Roan, Sorrel, Tobiano/Overo, and Other). In addition, interactive effects are considered including age's first and second order interaction with Mare and Gelding.

In contrast to in-person auctions, online auctions rely on the types of information available to the buyer. In order to understand the influence of the information provided, several indicators were recorded for background information and visualizations of the horse. Note Line Count is a count of the lines of notes provided by the seller regarding lineage, show or work performance, disciplinary details, or any other pertinent information that the seller wanted to provide potential buyers. While these differ in content based on the seller personal preferences, we recorded the number of lines to capture an indication of how much additional information buyers had access to outside the recorded variables. Just as the marketplaces for equine and livestock are changing, the ways in which information is provided to buyers is changing. Historically, buyers would have had access to an in-person demonstration of a horse which would provide information on workability, conformation, and disposition; this information is now provided, at best, as a video provided by the seller. To capture the buyers' access to visual representations of the horse, a count of specific types of pictures were recorded including: Front Picture, Back Picture, Side Picture, Both Side Picture (this is a binary to indicate whether both sides were represented visually), Action Shot (this indicated whether there was any type of shot showing the horse in motion or working), and Hoof Pictures. Conformational and hoof photographs show potential deformations and conformation irregularities that would be important for performance, showmanship, longevity, and future breeding potential. Videos, which are relatively new to horse auctions, provide visual evidence that would be evident at an in-person auction. Videos are the recorded count of videos provided on the horse listing. The quality and content of the video were not quantified, but understanding the value of videos can provide some information on how these sellers are changing to reflect the changes in the livestock marketplace.

Disposition Score is the mean score on a scale of 1 to 10 with 1 being the best and 10 being the worst for a series of disposition categories: general disposition, stall manners, farrier, clipping, and 
Table 1. Variable descriptions and summary statistics for monthly horse internet auctions 2013-2019

\begin{tabular}{|c|c|c|c|c|c|c|}
\hline Variable name & Variable descriptions & $\mathrm{N}$ & Mean & $\begin{array}{l}\text { Standard } \\
\text { deviation }\end{array}$ & Min & Max \\
\hline Real bid & Final bid in 2019 dollars & 2,122 & 3,167 & 3,062 & 94 & 31,352 \\
\hline Age & Age of horse in years & 2,274 & 5.76 & 4.55 & 0 & 23 \\
\hline Height & Height in inches & 1,743 & 61.77 & 2.86 & 20 & 71 \\
\hline Height available & $=1$ if horse height is listed & 2,274 & 0.77 & 0.42 & 0 & 1 \\
\hline Mare & $=1$ if horse is a mare & 2,274 & 0.60 & 0.49 & 0 & 1 \\
\hline Gelding & $=1$ if horse is a gelding & 2,274 & 0.29 & 0.46 & 0 & 1 \\
\hline Auction count & Count of horse lots each auction & 2,274 & 54.10 & 19.65 & 15 & 95 \\
\hline Repeat auction & $=1$ if horse is relisted in next auction & 2,274 & 0.10 & 0.30 & 0 & 1 \\
\hline Notes lines & Count of lines in note section & 2,274 & 8.67 & 6.02 & 0 & 55 \\
\hline Front picture & $\begin{array}{l}\text { Count of pictures of the front of the } \\
\text { horse }\end{array}$ & 2,274 & 0.71 & 0.73 & 0 & 5 \\
\hline Back picture & $\begin{array}{l}\text { Count of pictures of the back of the } \\
\text { horse }\end{array}$ & 2,274 & 0.64 & 0.53 & 0 & 3 \\
\hline Side picture & $\begin{array}{l}\text { Count of pictures of the side of the } \\
\text { horse }\end{array}$ & 2,274 & 2.04 & 0.96 & 0 & 6 \\
\hline Both side pictures & $\begin{array}{l}=1 \text { if pictures of both sides of horse } \\
\text { presented }\end{array}$ & 2,274 & 0.68 & 0.47 & 0 & 1 \\
\hline Action shot & $=1$ if action shot of horse presented & 2,274 & 0.29 & 0.45 & 0 & 1 \\
\hline Hoof pictures & Count of horse hoof pictures & 2,274 & 0.33 & 0.64 & 0 & 5 \\
\hline Videos & $\begin{array}{l}\text { Count of videos presented of the } \\
\text { auctioned horse }\end{array}$ & 2,274 & 1.00 & 1.05 & 0 & 5 \\
\hline AQHA breed & $=1$ if $\mathrm{AQHA}$ breed was indicated & 2,274 & 0.85 & 0.36 & 0 & 1 \\
\hline Repeat sire & $\begin{array}{l}=1 \text { if sire was listed } 5 \text { or more times in } \\
\text { all auctions }\end{array}$ & 2,274 & 0.43 & 0.49 & 0 & 1 \\
\hline Sire notes lines & Count of lines in sire note section & 2,274 & 8.15 & 9.97 & 0 & 69 \\
\hline Dam notes lines & Count of lines in dam note section & 2,274 & 5.84 & 9.85 & 0 & 109 \\
\hline Disposition score & Horse's mean disposition score ${ }^{1}$ & 2,274 & 1.78 & 0.82 & 1 & 8 \\
\hline Negative traits & $\begin{array}{l}=1 \text { if horse had any negative traits }{ }^{2} \\
\text { listed }\end{array}$ & 2,274 & 0.23 & 0.42 & 0 & 1 \\
\hline Discipline count & Count of the number of disciplines listed & 2,274 & 3.58 & 3.63 & 0 & 26 \\
\hline Breeding stock & $\begin{array}{l}=1 \text { if horse was indicated as breeding } \\
\text { stock }\end{array}$ & 2,274 & 0.37 & 0.48 & 0 & 1 \\
\hline Bay & $=1$ if horse color was listed as bay & 2,274 & 0.29 & 0.45 & 0 & 1 \\
\hline Black & $=1$ if horse color was listed as black & 2,274 & 0.03 & 0.16 & 0 & 1 \\
\hline Buckskin & $=1$ if horse color was listed as buckskin & 2,274 & 0.03 & 0.18 & 0 & 1 \\
\hline Chestnut & $=1$ if horse color was listed as chestnut & 2,274 & 0.14 & 0.35 & 0 & 1 \\
\hline Gray & $=1$ if horse color was listed as gray & 2,274 & 0.02 & 0.13 & 0 & 1 \\
\hline Palomino & $=1$ if horse color was listed as palomino & 2,274 & 0.08 & 0.27 & 0 & 1 \\
\hline Roan & $=1$ if horse color was listed as roan & 2,274 & 0.04 & 0.19 & 0 & 1 \\
\hline Sorrel & $=1$ if horse color was listed as sorrel & 2,274 & 0.33 & 0.47 & 0 & 1 \\
\hline
\end{tabular}


Table 1. (Continued)

\begin{tabular}{|c|c|c|c|c|c|c|}
\hline Variable name & Variable descriptions & $\mathrm{N}$ & Mean & $\begin{array}{l}\text { Standard } \\
\text { deviation }\end{array}$ & Min & Max \\
\hline Tobiano/overo & $\begin{array}{l}=1 \text { if horse color was listed as tobiano } \\
\text { or overo }\end{array}$ & 2,274 & 0.02 & 0.14 & 0 & 1 \\
\hline Other & $\begin{array}{l}=1 \text { if horse color was listed as other or } \\
\text { not listed }\end{array}$ & 2,274 & 0.03 & 0.17 & 0 & 1 \\
\hline All around & $=1$ if all-around class was listed & 2,274 & 0.30 & 0.46 & 0 & 1 \\
\hline $\begin{array}{l}\text { Hunter under } \\
\text { saddle }\end{array}$ & $\begin{array}{l}=1 \text { if the hunter under saddle discipline } \\
\text { was listed }\end{array}$ & 2,274 & 0.19 & 0.40 & 0 & 1 \\
\hline Halter & $=1$ if halter class was listed & 2,274 & 0.45 & 0.50 & 0 & 1 \\
\hline Reining & $=1$ if reining class was listed & 2,274 & 0.08 & 0.27 & 0 & 1 \\
\hline Western pleasure & $\begin{array}{l}=\text { if any western pleasure class was } \\
\text { listed }\end{array}$ & 2,274 & 0.36 & 0.48 & 0 & 1 \\
\hline Canada & $=1$ if listed in Canada & 2,274 & 0.01 & 0.11 & 0 & 1 \\
\hline Midwest & $=1$ if listed in Midwest & 2,274 & 0.28 & 0.45 & 0 & 1 \\
\hline Northeast & $=1$ if listed in Northeast & 2,274 & 0.09 & 0.28 & 0 & 1 \\
\hline South & $=1$ if listed in South & 2,274 & 0.55 & 0.50 & 0 & 1 \\
\hline West & $=1$ if listed in West & 2,274 & 0.08 & 0.27 & 0 & 1 \\
\hline
\end{tabular}

${ }^{1}$ Diposition categories include the following: general disposition, stall manners, farrier, clipping, and whether they get along with other horses, where 1 is best and 10 being the worse for the category.

${ }^{2}$ Negative traits are noted if the horse was described as a or having any of the following traits: cribber, weaver, nerved, foundered, parrot mouth, major surgery, colic/resection surgery, past lameness, or any other defects, abnormalities, or blemishes.

whether they get along with other horses. These are subjective to the seller's opinions and as to whether the seller indicated any of these. In order to maximize the usable data in estimations, the mean across these scores allows the analysis to use the complete set of data and generalizes any information on disposition provided. Negative Traits is a binary indication of whether the seller recorded any of the following negative traits: cribber, weaver, nerved, foundered, parrot mouth, major surgery, colic/resection surgery, past lameness, or any other defects, abnormalities, or blemishes.

In addition to horse and listing characteristics, horse lineage was recorded. All but a very small minority (less than $2 \%$ ) had a sire and dam listed. In order to differentiate across horses, Sire Note Lines and Dam Note Lines were recorded which are a count of the number of lines of notes the seller provided to describe the sire and dam of a horse. These vary greatly across the listings where sire ranges from 0 to 69 lines and dam notes range from 0 to 109 lines (Table 1). Knowing the sire is an important aspect of horse lineage, each sire was recorded. Using the full set of sire identities, a count of the number of progenies from each sire was calculated. If a sire had five (this number was used as it was a clear delineation in the sire progeny counts) or more horses listed in the entire sample, a binary variable was recorded for those listings (Repeat Sire). The aim is to estimate whether there is value in having a more popular sire relative to the sires represented in our sample.

Specific discipline training and use information was recorded for each horse listed. Discipline Count is a count of distinct disciplines listed for the horse. Several disciplines were recorded as a binary variable to investigate possible price premiums for horses with that designation: All Around, Hunter Under Saddle, Halter, Reining, and Western Pleasure. Similarly, Breeding Stock was also recorded to indicate potential buyer preferences for a horse described as current or potential breeding stock. 
Finally, to capture heterogeneity among different regions, horse location was recorded. This location was converted to indicator variables denoting the following regions as defined by the U.S. Department of Commerce (2013): Northeast, Midwest, South, West, and Canada.

\section{Methods}

To understand the factors that contribute to a horse's value and how auction characteristics contribute to their propensity to sell, two analyses will be estimated. The first will focus on a horse's propensity to sell which provides a greater level of understanding on the overall marketplace and how the information available aids buyers. The second analysis will focus on the horses that were purchased and will estimate a hedonic model to understand the decomposed value of a horse at auction. Because the choice to purchase a horse censors the hedonic pricing study data, this analysis uses a Heckman two-step approach in estimating the hedonic model.

\subsection{Propensity to Sell Modeling Methods}

For the propensity to sell model, the dependent variable ( $\mathrm{Sell}$ ) is a binary choice as to whether the horse sold or not. To model the factors that contribute to the sale of a horse, the probit model will be used. The probit model was first introduced by Bliss (1934) and has continued to be used extensively to estimate the conditional likelihoods across disciplines. A full exposition of the probit model is found throughout textbooks (Cameron and Trivedi, 2005; Greene, 2001). The following is a brief overview of the model. Probit regression models use a latent variable model approach such that:

$$
Y=\left\{1, \varepsilon<X^{\prime} \beta 0 ; 0 \text { otherwise }\right\}
$$

where $Y$ represents the decision to purchase a horse or not, $X$ represents the series of variables that contribute to the purchase decision, $\beta$ are the respective coefficients, and $\varepsilon$ represents the independent standard errors. The underlying likelihood is estimated using a standard normal distribution to determine the conditional probabilities. The log-likelihood model, which will be estimated using maximum likelihood procedures, is as follows:

$$
\ln L(Y, X)=\sum_{i=1}^{n}\left[\left(y_{i}\right) \ln \Phi\left(x_{i}^{\prime} \beta\right)+\left(1-y_{i}\right) \ln \Phi\left(1-x_{i}^{\prime} \beta\right)\right]
$$

where $\Phi$ represents the standard normal probability distribution and all other parameters previously defined. This model will be estimated with robust standard errors to correct for heteroskedasticity in the error terms.

In order to account for data censoring in the following analysis, the propensity to sell model will act as the selection criteria and be used as the first stage in the Heckman sample selection framework (Heckman, 1979). For each observation, the predicted value will be recorded as well as the probability distribution function (PDF) and cumulative distribution function (CDF). These will be used to calculate the inverse Mills ratio (IMR) (Equation 3) which will be included in the hedonic horse model to account for selection bias when only considering the horses that were sold during the internet auctions and to control for endogeneity.

$$
I M R=\frac{\phi\left(x^{\prime} \beta\right)}{\Phi\left(x^{\prime} \beta\right)} .
$$

For Equation 3, $\phi$ represents the PDF and $\Phi$ represents the CDF of the standard normal distribution (based on the assumptions used in the probit modeling framework) from the selection model. The IMR is calculated for each observation used in the hedonic price model. 


\subsection{Hedonic Price Modeling Methods}

Hedonic pricing models have been used extensively in the literature to better understand the value of product characteristics. For livestock prices specifically, the hedonic pricing model can elucidate changes in buyer preferences, management practices' effect on prices, and general market changes (Jabbar, 1998; Barrett et al., 2003; Zimmerman et al., 2012; Hagerman et al., 2017; Williams et al., 2006). For horse values specifically, Hansen and Stowe (2017), Taylor et al (2006), Maynard and Stoeppel (2007), Taylor and Sieverkropp (2013), and Vestal et al. (2015) all used hedonic modeling to estimate the price determinants of horses to represent types of markets, intended use of the horse, and policy changes.

Using the horse listings entered in a given online auction, a hedonic price model of the final bid price can decompose the value of a horse into the value of individual characteristics of that horse. Hedonic price modeling was first presented by Waugh (1928) who formally linked product characteristics to product prices. That model was later expanded and given theoretical foundations (Lancaster, 1971; Lucas, 1975; Hendler, 1975; Rosen, 1974). Hedonic modeling is based on the heterogeneity of a product and the underlying implicit value of the product characteristics. Differentiated products are a combination of observable and unobservable characteristics whose values total the final cost of the product. Using contract theory, in a competitive marketplace, the final price is determined by the meeting of the buyer's bid function and the seller's offer function. For auction data, when there is no meeting of these functions, the horse would not sell. Generally, the hedonic function can be expressed as follows:

$$
P_{i t}=F\left(O_{i t}, U_{i t}\right)+\varepsilon_{i t},
$$

where $P$ represents observable market prices, $O$ are the observable characteristics, $U$ are the unobservable characteristics, and $\varepsilon$ is the disturbance term for the $i^{\text {th }}$ good in time $t$. Econometrically, an ordinary least squares regression model can be used to estimate the value of the characteristics recorded. After testing for heteroskedasticity, the standard errors will be corrected with White's heteroskedastic consistent standard errors (White, 1980).

The hedonic model is the second stage in the Heckman sample selection model and will include the IMRs calculated following the propensity to sell estimation. Empirically, the Heckman model is estimated using Equation 5 as follows:

$$
\ln \left(\operatorname{RealP}_{i}\right)=x_{i}^{\prime} \beta+I M_{i}^{\prime} \delta+\varepsilon_{i t},
$$

where variables describing horse characteristics, auction descriptions, and temporal and spatial specifications are included in $x_{i}$, IMR represents the inverse Mill's ratio to address sample selection bias, $\beta$ and $\delta$ represent parameter coefficients, and $\varepsilon_{i t}$ are the robust standard errors. If the $\delta$ coefficient is not significant, it can indicate that sample selection bias was not statistically significant, however, based on a priori expectations and understanding of the data generating process, this can continue to be modeled (Taylor et al., 2006). Similar to Taylor et al. (2006) and Vestal et al. (2015), the natural $\log$ of the real price, i.e., seasonally adjusted price with a baseline of 2019, is used to better fit the data and account for inflationary adjustments in the prices. Because the semilogarithmic modeling framework, coefficients on binary variables should be transformed. Halvorsen and Palmquist (1980) presented the interpretation of semilogarithmic equations and whose derivations were furthered by Kennedy (1981). While Giles (1982) showed that for a sufficiently large sample both transformations were consistent, this work will use Kennedy's (1981) transformation equation as follows:

$$
g^{*}=e^{(\beta-0.5 V(\beta))}-1,
$$

where $g^{*}$ is the percentage change in the dependent variable reflecting a binary change in the dummy variable, $\beta$ represents the estimated coefficient, and $V(\beta)$ represents estimated variance of $\beta$. 


\section{Results and discussion}

All models were estimated using the software Stata, and results are presented in Tables 2 and 3. The results are consistent with Taylor et al. (2006) whose studies show quality quarter horses sold at live auction. We expect that the variation between parameter magnitude and significance may be related to the differences in auction type, information available, horse type, and years studied between the two analyses.

\subsection{Propensity to Sell Results}

Results from the propensity to sell model are presented in Table 2 and include the estimated marginal effects. The results are consistent with the literature as various factors significantly affected the likelihood of a horse selling at an internet auction. Of the 2,274 horse auction records, 2,053 were used in the propensity to sell model for auctions from 2013 to 2019 . The excluded observations are due to missing or incomplete data provided in the auction listing.

In terms of horse characteristics, age and sex did not have a statistically significant relationship with likelihood of selling, meaning that while there may be pricing differences, these factors are not changing the decision to buy. Color of horse did have an effect on purchasing decisions. Horses listed as "other" colors were $16.3 \%$ less likely to sell than the baseline, bay-colored horse. This may reflect a preference in purchasing decisions for traditional coloring over very rare coloring patterns. Finally, an AQHA registered horse was $6.9 \%$ more likely to sell over a horse that was not registered. This might indicate preferences for AQHA for competition purposes or might be a better indicator of the types of horses buyers prefer through Professional Horse Services.

In lieu of a physical inspection and physical marketplace, sellers entering a horse in an online auction determine the information presented to potential buyers. In terms of affecting the propensity to sell, listings with at least one action photograph reduce the likelihood of selling by $2.5 \%$. This may reflect the quality of the photos or that these pictures detract from other conformation pictures. Sellers may try to overcompensate for the market type, but provide too many of the "wrong pictures." In contrast, dam note lines increase the likelihood of selling by $0.3 \%$ for each additional line. These notes are additional pedigree and note potential performance indicators and often describe competition success of the dam and her offspring.

Performance and disposition indicators such as disposition score affect propensity to sell. Each additional mean point increases the likelihood of selling by $3.7 \%$ which is counterintuitive in that as the score increases the worse, the horse's disposition is ranked. This result may reflect a discounted horse resulting from a higher score. It is important to note that the mean disposition score is 1.79 , indicating while this marginal value holds, it is still more reflective of low, good scores. Additionally, each additional discipline listed reduces the likelihood of selling by $1.2 \%$. This could show that horses listed as being too diverse damage the likelihood of selling. In common terms, being a jack of all trades but a master of none has a negative effect on a horse's propensity to sell. Alternately, this could reflect a higher reservation price by the seller to account for the value added from the additional discipline training. Finally, a horse listed as current or potential breeding stock increased the likelihood of selling by $9.8 \%$, potentially reflecting buyer's preferences for breeding potential and potential future earnings in purchasing decisions.

Temporally, there have been changes to propensity to sell. First, March has an increased likelihood to sell compared to January, 9.7\%, while horses listed in July were $7.3 \%$ less likely to sell. This result may reflect buyers looking during the spring for a new horse to compete in the summer who are less likely to buy in the middle of a competition season as they are campaigning the horse they currently have. Annually, there has been a decreasing trend for horses to successfully sell online. In comparison to 2013, each subsequent year horses was less likely to sell. Compared to 2013, horses selling in 2015 were $21.8 \%$ less likely to sell while horses auctioned in 2019 were $35.9 \%$ less likely to 
Table 2. Propensity to sell model regression results estimating factors contributing to purchase decision for monthly internet horse auctions 2013-2019; $\mathrm{N}=2,053$

\begin{tabular}{|c|c|c|c|}
\hline Variable & Coefficient & Robust standard error & Marginal effects ${ }^{a}$ \\
\hline Constant & 1.028 & 0.289 & \\
\hline Real bid & 0.000 & 0.000 & 0.000 \\
\hline \multicolumn{4}{|l|}{ Horse characteristics } \\
\hline Age & 0.006 & 0.084 & 0.001 \\
\hline Age*age & -0.001 & 0.006 & \\
\hline Mare & -0.105 & 0.189 & 0.004 \\
\hline Mare*age & 0.021 & 0.086 & \\
\hline Mare*age*age & 0.000 & 0.006 & \\
\hline Gelding & 0.176 & 0.225 & 0.053 \\
\hline Gelding*age & -0.049 & 0.098 & \\
\hline Gelding*age*age & 0.005 & 0.007 & \\
\hline Height available & -0.071 & 0.078 & \\
\hline Black & 0.239 & 0.193 & 0.081 \\
\hline Buckskin & -0.123 & 0.167 & -0.044 \\
\hline Chestnut & -0.067 & 0.100 & -0.024 \\
\hline Gray & 0.113 & 0.225 & 0.039 \\
\hline Other & -0.451 & 0.184 & $-0.163^{\star \star}$ \\
\hline Palomino & -0.048 & 0.122 & -0.017 \\
\hline Roan & -0.083 & 0.162 & -0.029 \\
\hline Sorrel & -0.057 & 0.078 & -0.020 \\
\hline Tobiano/overo & -0.289 & 0.225 & -0.104 \\
\hline AQHA breed & 0.194 & 0.089 & $0.069^{\star \star}$ \\
\hline \multicolumn{4}{|c|}{ Auction information provided } \\
\hline Repeat auction & -0.404 & 0.103 & $-0.143^{\star \star \star}$ \\
\hline Auction count & -0.006 & 0.002 & $-0.002^{\star \star}$ \\
\hline Notes lines & -0.008 & 0.006 & -0.003 \\
\hline Front picture & 0.006 & 0.049 & 0.002 \\
\hline Back picture & 0.075 & 0.064 & 0.027 \\
\hline Side picture & 0.042 & 0.040 & 0.015 \\
\hline Both side pictures & -0.079 & 0.082 & -0.028 \\
\hline Action shot & -0.071 & 0.032 & $-0.025^{\star *}$ \\
\hline Hoof pictures & -0.018 & 0.050 & -0.006 \\
\hline Videos & -0.007 & 0.035 & -0.003 \\
\hline Repeat sire & -0.065 & 0.068 & -0.023 \\
\hline Sire notes lines & 0.002 & 0.004 & 0.001 \\
\hline Dam notes lines & 0.009 & 0.004 & $0.003^{\star \star}$ \\
\hline
\end{tabular}

(Continued) 
Table 2. (Continued)

\begin{tabular}{|c|c|c|c|}
\hline Variable & Coefficient & Robust standard error & Marginal effects ${ }^{a}$ \\
\hline \multicolumn{4}{|c|}{ Performance and disposition } \\
\hline Disposition score & 0.103 & 0.040 & $0.037^{\star \star}$ \\
\hline Negative traits & -0.053 & 0.071 & -0.019 \\
\hline Discipline count & -0.035 & 0.013 & $-0.012^{\star \star \star}$ \\
\hline Breeding stock & 0.276 & 0.081 & $0.098^{\star \star \star}$ \\
\hline All around & -0.014 & 0.078 & -0.005 \\
\hline Hunter under saddle & 0.113 & 0.089 & 0.040 \\
\hline Halter & 0.004 & 0.071 & 0.001 \\
\hline Reining & -0.139 & 0.130 & -0.049 \\
\hline Western pleasure & 0.085 & 0.075 & 0.030 \\
\hline \multicolumn{4}{|l|}{ Temporal factors } \\
\hline February & 0.117 & 0.126 & 0.041 \\
\hline March & 0.288 & 0.140 & $0.097^{\star \star}$ \\
\hline April & -0.069 & 0.130 & -0.025 \\
\hline May & -0.127 & 0.112 & -0.045 \\
\hline June & 0.073 & 0.148 & 0.026 \\
\hline July & -0.203 & 0.122 & $-0.073^{\star}$ \\
\hline August & -0.127 & 0.113 & -0.045 \\
\hline September & -0.193 & 0.167 & -0.070 \\
\hline December & -0.146 & 0.133 & -0.052 \\
\hline Year 2014 & -0.686 & 0.168 & $-0.209^{\star * \star}$ \\
\hline Year 2015 & -0.712 & 0.170 & $-0.218^{\star \star \star}$ \\
\hline Year 2016 & -0.874 & 0.186 & $-0.277^{\star \star \star}$ \\
\hline Year 2017 & -0.885 & 0.169 & $-0.281^{\star \star \star}$ \\
\hline Year 2018 & -0.886 & 0.171 & $-0.282^{\star \star \star}$ \\
\hline Year 2019 & -1.093 & 0.193 & $-0.359^{\star \star \star}$ \\
\hline \multicolumn{4}{|l|}{ Spatial factors } \\
\hline Canada & -0.070 & 0.258 & -0.025 \\
\hline Northeast & -0.001 & 0.118 & $-0.001^{\star *}$ \\
\hline South & 0.144 & 0.069 & 0.051 \\
\hline West & -0.021 & 0.123 & -0.007 \\
\hline
\end{tabular}

a $P<0.1, P<0.05$, and $P<0.01$ represented by ${ }^{*},{ }^{* *}$, and ${ }^{* \star *}$, respectively.

sell. This decrease in propensity to sell may be reflective of the changing market structures where more horses are listed of varying quality levels or that internet auctions may allow for some levels of adverse selection, where horses that do not sell in person or by word of mouth are moved online potentially reducing their desirability. 
Table 3. Hedonic price model regression for monthly internet horse auctions 2013-2019; N=930

\begin{tabular}{|c|c|c|c|c|}
\hline Variable & Coefficients & $\begin{array}{c}\text { Robust standard } \\
\text { errors }\end{array}$ & $\begin{array}{c}\text { Transformed } \\
\text { parameters }\end{array}$ & Significance $^{a}$ \\
\hline Constant & 5.116 & 0.964 & - & 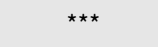 \\
\hline Inverse Mills ratio & -1.816 & 0.409 & - & $* * *$ \\
\hline \multicolumn{5}{|l|}{ Horse characteristics } \\
\hline Age & 0.262 & 0.066 & - & $\star \star \star *$ \\
\hline Age*age & -0.013 & 0.004 & - & $* \star *$ \\
\hline Mare & 0.484 & 0.183 & 0.481 & $\star \star \star *$ \\
\hline Mare*age & -0.257 & 0.069 & - & $* * *$ \\
\hline Mare ${ }^{\star}$ age ${ }^{\star}$ age & 0.011 & 0.004 & - & $\star \star \star *$ \\
\hline Gelding & -0.250 & 0.205 & -0.297 & \\
\hline Gelding*age & -0.100 & 0.077 & - & \\
\hline Gelding*age*age & 0.001 & 0.005 & - & \\
\hline AQHA breed & -0.073 & 0.100 & - & \\
\hline Height & 0.043 & 0.016 & - & $\star \star \star *$ \\
\hline Black & -0.253 & 0.174 & -0.288 & \\
\hline Buckskin & 0.075 & 0.130 & 0.010 & \\
\hline Chestnut & 0.024 & 0.085 & -0.018 & \\
\hline Gray & -0.364 & 0.186 & -0.367 & * \\
\hline Other & 0.234 & 0.163 & 0.165 & \\
\hline Palomino & 0.207 & 0.092 & 0.175 & ** \\
\hline Roan & 0.397 & 0.124 & 0.398 & $\star \star \star *$ \\
\hline Sorrel & -0.127 & 0.066 & -0.148 & * \\
\hline Tobiano/overo & 0.466 & 0.273 & 0.390 & * \\
\hline \multicolumn{5}{|c|}{ Auction information provided } \\
\hline Auction counts & 0.000 & 0.002 & - & \\
\hline Notes lines & 0.037 & 0.007 & 0.034 & $\star \star \star$ \\
\hline Front picture & 0.005 & 0.043 & - & \\
\hline Back picture & -0.140 & 0.056 & - & $\star \star *$ \\
\hline Side picture & -0.121 & 0.033 & - & $\star \star \star *$ \\
\hline Both side pictures & 0.098 & 0.070 & 0.065 & \\
\hline Action shot & 0.180 & 0.031 & 0.179 & $\star \star \star \star ~$ \\
\hline Hoof pictures & 0.140 & 0.037 & - & $\star \star \star$ \\
\hline Videos & 0.108 & 0.031 & - & $\star \star \star *$ \\
\hline Repeat sire & 0.203 & 0.060 & 0.189 & $\star \star \star *$ \\
\hline Sire notes lines & 0.001 & 0.003 & - & \\
\hline Dam notes lines & -0.002 & 0.003 & - & \\
\hline
\end{tabular}


Table 3. (Continued)

\begin{tabular}{|c|c|c|c|c|}
\hline Variable & Coefficients & $\begin{array}{c}\text { Robust standard } \\
\text { errors }\end{array}$ & $\begin{array}{l}\text { Transformed } \\
\text { parameters }\end{array}$ & Significance \\
\hline \multicolumn{5}{|c|}{ Performance and disposition } \\
\hline Disposition score & -0.262 & 0.042 & - & 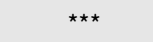 \\
\hline Negative traits & -0.058 & 0.062 & -0.085 & \\
\hline Discipline count & 0.026 & 0.015 & - & * \\
\hline Breeding stock & -0.256 & 0.094 & -0.261 & $\star \star \star *$ \\
\hline All around & 0.211 & 0.072 & 0.191 & $\star \star * *$ \\
\hline Hunter under saddle & -3.715 & 1.683 & -0.990 & ** \\
\hline $\begin{array}{l}\text { Hunter under } \\
\text { saddle*height }\end{array}$ & 0.054 & 0.027 & 0.042 & ** \\
\hline Halter & 0.069 & 0.061 & 0.039 & \\
\hline Reining & 0.418 & 0.134 & 0.421 & $\star \star \star$ \\
\hline Western pleasure & 0.063 & 0.069 & 0.029 & \\
\hline \multicolumn{5}{|l|}{ Temporal factors } \\
\hline February & 0.097 & 0.104 & 0.046 & \\
\hline March & -0.157 & 0.125 & -0.197 & \\
\hline April & 0.221 & 0.106 & 0.183 & $\star \star *$ \\
\hline May & 0.454 & 0.094 & 0.503 & $\star \star \star *$ \\
\hline June & 0.233 & 0.112 & 0.193 & ** \\
\hline July & 0.284 & 0.107 & 0.260 & $\star \star \star \star ~$ \\
\hline August & 0.141 & 0.095 & 0.098 & \\
\hline September & 0.310 & 0.166 & 0.255 & * \\
\hline December & 0.470 & 0.122 & 0.505 & $\star \star \star *$ \\
\hline Year 2014 & 0.577 & 0.182 & 0.625 & $\star \star \star *$ \\
\hline Year 2015 & 0.592 & 0.188 & 0.646 & $\star \star \star *$ \\
\hline Year 2016 & 1.140 & 0.228 & 1.789 & 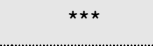 \\
\hline Year 2017 & 0.794 & 0.215 & 0.986 & $\star \star \star *$ \\
\hline Year 2018 & 0.953 & 0.212 & 1.333 & $\star \star \star \star$ \\
\hline Year 2019 & 1.199 & 0.262 & 1.909 & 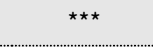 \\
\hline \multicolumn{5}{|l|}{ Spatial factors } \\
\hline Canada & 0.951 & 0.389 & 1.129 & ** \\
\hline Northeast & -0.050 & 0.098 & -0.094 & \\
\hline South & -0.087 & 0.070 & -0.115 & \\
\hline West & -0.131 & 0.107 & -0.169 & \\
\hline
\end{tabular}

${ }^{a *},{ }^{* *}$, and ${ }^{* * *}$ represent $P<0.1, P<0.05$, and $P<0.01$, respectively. 


\subsection{Hedonic Modeling Results}

Hedonic pricing model results are presented in Table 3 including the transformed parameters for all binary variables. The hedonic modeling represents the 930 observations that were both complete and sold at auction, approximately $41 \%$ of the total sample.

Mares and fillies sell for $48.1 \%$ more than stallions while gelding sale prices were not statistically different. Similarly, age affects the different sexes heterogeneously. Stallions increase in value as their ages increase but at a decreasing rate when considering the sign on the second order age variable. This could show a value preference for more mature and accomplished horses compared to younger, less-trained counterparts. This can also show the value for breeding potential (for stallions) but that this impact on values slows at a certain point. Conversely, as female horses age, their value decreases but at an increasing rate in comparison to male horses.

The value for color preferences is statistically significant with gray and sorrel horses commanding a lower value compared to bay horses while palomino, roan, and tobiano/overo colored horses selling for a premium. Height was also statistically significant with taller horses receiving a premium. To ensure veracity of claims made, the auction company encourages sellers indicate a horse's height with verifiable means (measuring stick) and any inaccuracies can result a strictly enforced return policy where the seller must receive any returned horse due to misrepresentation.

While horse characteristics often reflect buyer preferences, the length and detail regarding horse characteristics are completely in the control of the seller in a virtual marketplace. The auction information provided by the seller sheds insights into the buying decision and the value of information a seller decided to provide for buyers. For each additional line of notes about the horse, the sale price increased $3.4 \%$, on an average. Pictures depicting a horse in use and of their hooves increased sale price while back and side pictures had a negative impact on sale price. Action shots decrease the likelihood of being purchased, but increase the value when they are purchased, perhaps indicating that when the quality of the horse or extent of training is high enough the action shot commands a premium. While Front Picture was not significant, it would be important to potentially distinguish this as an expected conformation image the buyer expects. The front picture would not increase the perceived value, rather it would indicate a conformational deformity. As such, providing a front picture does not significantly affect the value. Side and back photographs decrease the value and can be explained much like front photographs, where these photographs would more likely be used as a discounting tool due to some phenotypic characteristic observed in the photograph rather than motivating a higher bid. According to Plant and Stowe (2013), these types of voluntary information reduce asymmetric information and are valuable regardless of their impact on final bid price.

With the evolving market structure, changes in the way in which information about a good is conveyed are realized. Horses listed with videos of the horse in use or with a popular sire received higher prices. The number of videos presented of the horse increases the price of auction horses by almost $11 \%$. While pictures depict conformation, these are static. Videos allow for a more immersive buyer experiences in making the most informed decision on horse conformation, suitability, and level of training, which is a change from auctions with only catalog information. With the increased availability of quality devices to create and edit videos, this result is particularly positive for sellers who choose to make those efforts. Horses sired by a sire who was in the data set 5 or more times sold for $18.9 \%$ more than those with sires receiving less representation. That means that recognizable and repeat sires do bring a premium over horses with a lesser known sire. This result makes sense as most stock-type horses are bred through artificial insemination, and one sire has the ability to breed hundreds of mares each year. Because of this, quality sires are in higher demand for their services.

For horse performance, all but negative traits, western pleasure, and halter significantly contributed to horse value. Higher average disposition scores, implying a less desirable horse with 
poor disposition, decrease the value by $26.2 \%$ per point increase. Each additional discipline listed increases sale price by $2.6 \%$ while horses listed as all around (horses with this designation typically indicate a horse that would be suitable for competition in many different disciplines and has not been focused on just one) and reining receive price premiums of $19.1 \%$ and $42.1 \%$, respectively. Horses listed as breeding stock sold for $26.1 \%$ less than those who were not. Horses described with training in hunter under saddle had price discounts. However, the interaction with the binary hunter under saddle variable and height indicates that taller horses with this designation sell for $4.2 \%$ more for each additional inch of height.

Monthly effects indicate there is heterogeneity in horse value based on time of year. January through March as well as August have the lowest prices. In comparison, December and May prices have the highest comparative value. Horses sold in December and May each have a 50\% value premium over horses sold in January. This premium for December sale horses may have several explanations such as the absence of online auctions in October and November, horses purchased for the December holiday gifts, successful show horses being offered at the end of the competition season, or due to tax-related purchases including tax write-offs and deductions. Similarly, premiums paid for May sale horses may reflect an upcoming show season when buyers may be searching for a horse to compete with. Annual effects show increases in the real value of horses from 2013 to 2019 with a spike in real prices in 2016. These prices may reflect macroeconomic conditions and the market for stock-type horses. Overall, real prices have trended upward over the study period.

\section{Conclusion}

Equine markets are unique types of livestock markets due to the working and recreational nature of horses as compared to cattles which are typically purchased for breeding or market. Over the past decade, there has been a shift in how animals have been purchased and sold. For horses, the emergence of online auctions connecting buyers and sellers nationally has facilitated a broader trading environment. This research has shown that the type of information provided does change the likelihood of selling a horse online and the value of a horse in providing more perfect information to buyers as compared to in-person auctions. It should be noted that many horses are exchanged through private sales in which potential sellers may view in person and, when appropriate, ride the horse providing experience with the animal which is not possible through most auction settings whether online or in-person.

It is economically understood that a successful transaction will only occur if a buyer's bid function is tangential to a seller's bid function or reserve price. This work estimated those factors that contribute to this meeting and the decomposition of the final price. Information such as breed, disposition scoring, and potential for breeding allow the buyer to more accurately value a horse and meet the seller's reservation price. In terms of value, there are limits to what information increases the value of a horse and what causes a negative impact on price. Higher values are associated with video media which might indicate a movement away from static information and a desire from buyers to want to have the dynamic movements of horses as a second-best alternative to in-person viewings. Overall, it has become more challenging for horses to sell, potentially due to the desire for more information from buyers and a recalibration of price expectations across the marketplace, but there is evidence of increasing real prices for horses that do sell. This trend may be influenced, in part because of fewer buyers in the marketplace. The data used for this study include one primary breed of horse, nonracing stock-type horses. Future work should aim to decompose sale price for other breeds, in particular nonracing horses. While continued work can be carried out to better understand the equine market and the actors in it, this analysis does provide some hope to this smaller industry that changes in selling practices can be economically beneficial and realized. 
Financial support. This research received no specific grant from any funding agency, commercial, or not-for-profit sectors.

Conflicts of interest. None.

\section{References}

Barrett, C.B., F. Chabari, D. Bailey, P.D. Little, and D.L. Coppock. "Livestock Pricing in the Northern Kenyan Rangelands." Journal of African Economies 12,2(2003):127-55.

Bender, K. and C.J. Stowe. "Home off the Range: The Role of Wild Horse Internet Adoptions in Informing Sustainable Western United State Rangeland Management.” Sustainability 12,1(2020):279.

Bliss, C.I. “The Method of Probits." Science 79,2037(1934):38-9.

Cameron, A.C., and P.K. Trivedi. Microeconometrics: Methods and Applications. New York, NY: Cambridge University Press, 2005.

Chezum, B. and B. Wimmer. "Roses or Lemons: Adverse Selection in the Market for Thoroughbred Yearlings." The Review of Economic Statistics 79,3(1997):521-26.

Giles, D.E.A. "The Interpretation of Dummy Variables in Semilogarithmic Equations: Unbiased Estimation." Economics Letters 10,1(1982):77-79.

Greene, W.H. Econometric Analysis. 7th Edition. Upper Saddle River, NJ: Prentice Hall, 2001.

Hagerman, A.D., J.M. Thompson, C. Ham, and K.K. Johnson. "Replacement Beef Cow Valuation under Data Availability Constraints." Frontiers in Veterinary Science 4(2017):185.

Halvorsen, R., and R. Palmquist. "The Interpretation of Dummy Variables in Semilogarithmic Equations." The American Economic Review 70,3(1980):474-75.

Hansen, C.R., and C.J. Stowe. "Determinants of Weanling Thoroughbred Auction Prices." Journal of Agricultural and Applied Economics 50,1(2017):48-63.

Heckman, J.J. “Sample Selection Bias as a Specification Error.” Econometrica 47,1(1979):153-61.

Hendler, R. "Lancaster's New Approach to Consumer Demand and its Limitations." The American Economic Review (1975):194-99.

Jabbar, M.A. “Buyer Preferences for Sheep and Goats in Southern Nigeria: A Hedonic Price Analysis.” Agricultural Economics 18,1(1998):21-30.

Kennedy, P.E. "Estimation with Correctly Interpreted Dummy Variables in Semilogarithmic Equations." American Economic Review 71,4(1981):801.

Lancaster, K. Consumer Demand: A New Approach. New York: Columbia University Press, 1971.

Lansford Jr, N.H., D.W. Freeman, D.R. Topliff, and O.L. Walker. "Hedonic Pricing of Race-bred Yearling Quarter Horses Produced by Quarter Horse Sires and Dams." Journal of Agribusiness 16,2(1998):169-85.

Lucas, R.E.B. "Hedonic Price Functions." Economic Inquiry 13,2(1975):157-78.

Maynard, L.J., and K.M. Stoeppel. "Hedonic Price Analysis of Thoroughbred Broodmares in Foal." Journal of Agribusiness 25,2(2007):181-95.

Neibergs, J.S. “A Hedonic Price Analysis of Thoroughbred Broodmare Characteristics." Agribusiness 17,2(2001):299-314.

Plant, E.J., and C.J. Stowe. "The Price of Disclosure in the Thoroughbred Yearling Market." Journal of Agricultural and Applied Economics 45,2(2013):243-25.

Poerwanto, D. and C.J. Stowe. "The Relationship Between Sire Representation and Average Yearling Prices in the Thoroughbred Industry." Journal of Agribusiness 21,1(2010):61-74.

Professional Horse Services, LLC. "Results.” Pro Horse Services, 2019. Internet site: https://prohorseservices.com/results/ (Accessed November 23, 2019).

Robert, M. and C.J. Stowe. "Ready to Run: Price Determinants of Thoroughbreds from Two-Year-Olds in Training Sales." Applied Economics 48,48(2016):4690-97.

Rosen, S. "Hedonic Prices and Implicit Markets: Product Differentiation in Pure Competition." Journal of Political Economy 82,1(1974):34-55.

Stowe, C.J. and M.L. Kibler. "Characteristics of Adopted Thoroughbred Racehorses in Second Careers." Journal of Applied Animal Welfare Science 19,1(2016):81-89.

Taylor, M., and E. Sieverkropp. "The Impacts of U.S. Horse Slaughter Plant Closures on a Western Regional Horse Market." Journal of Agricultural and Resource Economics 38,1(2013):48-63.

Taylor, M.R., K.C. Dhuyvetter, T.L. Kastens, M. Douthit, and T.L. Marsh. "Show Quality Quarter Horse Auctions: Price Determinants and Buy-Back Practices.” Journal of Agricultural and Resource Economics 31,3(2006):595-615.

U.S. Department of Agriculture, Agricultural Marketing Service. National Feeder \& Stocker Cattle Receipts. Washington, DC: U.S. Department of Agriculture, Agricultural Market News No. SJ_LS850, 2020.

U.S. Department of Commerce, Census Bureau. “Census Regions and Divisions of the United States.” Washington, DC: U.S. Department of Commerce, 2013. Internet site: https://www2.census.gov/geo/pdfs/maps-data/maps/reference/us_regdiv. pdf (Accessed November 22, 2019). 
Vestal, M.K., J.L. Lusk, S.R. Cooper, and C.E. Ward. "What are the Consequences of the Equine Slaughter Ban on Horse Prices?" Journal of Agricultural and Applied Economics 47,1(2015):27-46.

Vickner, S.S., and S.I. Koch. "Hedonic Pricing, Information, and the Market for Thoroughbred Yearlings." Journal of Agribusiness 19,2(2001):173-89.

Waugh, F.V. "Quality Factors Influencing Vegetable Prices." Journal of Farm Economics 10,2(1928):185-96.

White, H. "A Heteroskedasticity-Consistent Covariance Matrix Estimator and a Direct Test for Heteroskedasticity." Econometrica 48,4(1980):817-38.

Williams, O.T., I. Okike, B. Spycher, and others. "A Hedonic Analysis of Cattle Prices in the Central Corridor of West Africa: Implications for Production and Marketing Decisions.” In International Association of Agricultural Economists Conference. Gold Coast, Australia, 2006.

Zimmerman, L.C., T.C. Schroeder, K.C. Dhuyvetter, K.C. Olson, G.L. Stokka, J.T. Seeger, and D.M. Grotelueschen. “The Effect of Value-Added Management on Calf Prices at Superior Livestock Auction Video Markets." Journal of Agricultural and Resource Economics 37,1(2012):128-43.

Cite this article: Kibler ML and Thompson JM (2020). Price Determinants of Stock-Type Horses Sold at Public Online Auctions. Journal of Agricultural and Applied Economics 52, 596-612. https://doi.org/10.1017/aae.2020.20 